\title{
New approaches to maximization: evidence of correlations with malaise and well-being in the chilean adult population*
}

\section{Nuevos enfoques de maximización: evidencia de correlaciones con malestar y bienestar en población chilena adulta}

\author{
Emilio Moyano-Díaz $\stackrel{\text { ORCID }}{\longrightarrow}$ Rodolfo Mendoza-Llanos 2 ORCID \\ ${ }^{1}$ Universidad de Talca \\ ${ }^{2}$ Universidad del Bío-Bío \\ Chile
}

Fecha correspondencia:

Recibido: marzo 8 de 2019.

Aceptado: octubre 11 de 2019.

\section{Forma de citar:}

Moyano-Díaz, E., \& Mendoza-

Llanos, R. (2020). New approaches

to maximization: evidence of

correlations with malaise and well-

being in the Chilean adult population.

Rev. CES PSico, 13(1), 18-31.

\section{Open access}

(c) Copyright

Licencia creative commons

Etica de publicaciones

Revisión por pares

Gestión por Open Journal System

DOl: http://dx.doi.org/10.21615/

cesp.13.1.2

ISSN: 2011-3080

Sobre el artículo:

${ }^{*}$ This research was funded by the National Fund for Scientific and Technological Development from

\section{Abstract}

There is a lack of theoretical consensus about the decision-making process and particularly regarding the maximization construct. Recently, two conceptual approaches to maximization and their respective instruments were proposed. The first defines maximization as consisting of two dimensions, goal and strategy. The second differentiates between the two types of maximization according to the way an individual makes decisions, one is resolute and the other is fearful. Regarding the first approach, empirical goal and strategy relationships with emotional consequences on well-being and discomfort are unknown while deciding, while it is doubt whether the distinction proposed in the second approach also applies to the adult population and in contexts different from the European one. Empirical associations are evaluated here for each approach regarding indicators of malaise and well-being through a set of hypotheses. A sample of 624 Chilean adults of both sexes (20 to 70 years old) answered eight instruments on maximization, its components and types, and well-being and malaise. The results for both approaches show greater associations with rates of malaise than well-being. The results for the first approach show a more intense association with indices of malaise and well-being for strategy than goal. In the second approach, these associations are stronger and greater for fearful maximization than for resolute. The results contribute by increasing the understanding of the maximization construct by simultaneously showing that the increment in the strategy search for alternatives and the fearful style of maximization are directly associated with difficulty in deciding and regret.

Keywords: Maximization, Maximizing Behavior, Satisficing Behavior, Decision Making, Malaise, Regret, Well-Being.

\section{Resumen}

Existe carencia de consenso teórico acerca del proceso de tomar decisiones y particularmente respecto del constructo maximización. Recientemente, se propuso dos enfoques conceptuales sobre maximización y sus respectivos 
the Chilean Government, FONDECYT No. 1170855, awarded to the first author.

Sobre los autores:

1. Doctor en Psicología.

Psicólogo. Profesor Titular de Excelencia, Facultad de Psicología, Universidad de Talca, Chile. Miembro del Grupo de Investigación en Calidad de Vida y Ambientes Saludables (GICVAS) de la Universidad de Talca.

2. Becario Doctoral por la Universidad de Talca. Magister en Psicología Social. Psicólogo. Profesor Asistente, Escuela de Psicología, Universidad del Bío-Bío, Chile. instrumentos de evaluación. El primero considera que el concepto de maximización está constituido por dos dimensiones, meta y estrategia. El segundo diferencia entre dos tipos de maximización según el modo de decidir de un individuo, uno resuelto y otro temeroso. Respecto del primer enfoque se desconocen eventuales relaciones empíricas de meta y estrategia con consecuencias emocionales sobre el bienestar y malestar mientras se decide, mientras existe la duda si la distinción propuesta en el segundo enfoque se aplica también a población de adultos y en contextos diferentes al europeo. En el presente trabajo son evaluadas asociaciones empíricas para cada enfoque respecto de indicadores de malestar y bienestar mediante un conjunto de hipótesis. Una muestra de 624 adultos chilenos de ambos sexos (20 a 70 años) respondió ocho instrumentos sobre maximización, sus componentes y sus tipos, y su bienestar y malestar. Los resultados para ambos enfoques muestran asociaciones mayores con índices de malestar que de bienestar. Los resultados para el primer enfoque muestran asociación con índices de malestar y bienestar más intensos para la dimensión de estrategia que la de meta. En el segundo enfoque estas asociaciones son fuertes y mayores para el tipo de maximización temerosa que para resuelta. Los resultados contribuyen a incrementar la comprensión del constructo de maximización, al mostrar simultáneamente que el aumento en la estrategia de búsqueda de alternativas y el estilo temeroso de maximización, se asocian directamente con dificultad para decidir y con experimentar pesar.

Palabras clave: Maximización, Comportamiento Maximizador, Comportamiento Satisfactorio, Toma de Decisiones, Malestar, Pesar, Bienestar.

\section{Introduction}

The rational choice theory was dominant in the subject of decisions until criticism was made by Simon during the 1950s who modified it with his conceptualization of bounded rationality. The latter is also known as the model of procedural rationality, as it is a matter of deliberation, information processing or reasoning (Simon, 1955).

From this fruitful formulation, Schwartz et al. (2002) and Schwartz (2004) sought to explain the individual differences in decision making by means of a maximization model constituted by: decision difficulty (DD), high standards (HS) and search of alternatives (SA). The concept of maximization was prioritized and defined as the choice of optimal option. Maximization was conceived as a bipolar dimension with maximization at one end and satisficing on the other, wherein the latter was defined as the choice just good enough. Schwartz et al. (2002) and Nenkov, Morrin. Ward, Schwartz and Huyan (2008) showed that maximization is related to a range of psychological correlates, including regret, happiness, depression, optimism, self-esteem, perfectionism, neuroticism and subjective wellbeing. The maximizers exhibit a different style of decision-making from satisficers. They also experience higher levels of regret and dissatisfaction than satisficers, and are less happy, more depressed and less optimistic than satisficers (Iyengar et al., 2006). Purvis, Ryan and lyer (2011) inform that maximization correlates negatively with satisfaction with life (SWL) and positively with regret. In 2004, Schwartz proposed that the tendency to maximize is causally linked to lowered well-being because maximizers sacrifice limited resources in order to seek out more options.

Numerous studies in Anglo-Saxons and mainly student populations have been carried out with this conceptualization. However, currently, DD is considered a consequence of a decision (Cheek \& Schwartz, 2016). Additionally, SA show contradictory results as they appear to correlate negatively (Duriník, Procházka, \& Cígler, 2018; Newman, 
The literature regarding the measurement of maximization appears confused and fragmented with a lot of different definitions and scales for measuring maximization (Misuraca et al., 2015) and has shown contradictory results.
Schug, Yuki, Yamada, \& Nezlek, 2018) and other studies show a positive correlation with SWL and happiness (Moyano-Díaz, Martínez-Molina, \& Ponce, 2014; Turner, Rim, Betz, \& Nygren, 2012). In turn, regarding the satisficing pole, the hypotheses predicted in the theory have not always been confirmed since the positive emotional effects expected in those who choose satisficing is not as clear or strong (Abbe. Tkach, \& Lyubomirsky, 2003; Dar-Nimrod, Rawn, Lehman, \& Schwartz, 2009; Iyengar, Wells, \& Schwartz, 2006). On the other hand, there are some studies showing that the negative relationship between maximization and SWL is mitigated (Diab, Gillespie, \& Highhouse, 2008) or in another it is positive (Rim, Turner, Betz, \& Nygren, 2011). Even Lai (2010) informed that maximization is unrelated with regret. Weinhardt, Morse, Chimeli and Fisher (2012) showed that maximizers are not unhappy but are distressed while making decisions.

In respect to making decisions, Turner, Rim, Betz and Nygren (2012) using the Maximization Inventory (MI) shows that maximizers are less happy than satisficers, and that they make both, the best and the worst decisions too. They also inform that numerous studies found that maximizers when compared to satisficers experienced more post-decisional dissatisfaction, regret, heightened levels of stress, anxiety, depression during the decision-making process, engage in more social comparison and are less satisfied with their lives. In addition, they showed that the maximizers were positively correlated with maladaptive decision-making styles while satisficers were associated with well- adaptive styles and with good mental health. On the other hand, Misuraca and Teuscher (2013) showed that maximizers engage in non-productive decisional behavior and they are associated with negative indices of well-being. In the same vein, and more recently, Misuraca, Faraci, Gargemi, Carmeci and Miceli (2015) showed the existence of one type of maximizer -Fearful maximizer-who is positively associated with depression and regret, and negatively associated to self- esteem, optimism and SWL.

So, the literature regarding the measurement of maximization appears confused and fragmented with a lot of different definitions and scales for measuring maximization (Misuraca et al., 2015) and has shown contradictory results. At present, the structure of the maximization, construct initially proposed by Schwartz et al. (2002), is discussed along with its conceptualization and measurement. There are those who consider that the definition of maximizing is inadequate and that a theoretical or conceptual effort is necessary to build a better definition (Dalal, Diab, Zhu, \& Hwang, 2015; Misuraca \& Fasolo, 2018). There has also been criticism that that much of the discussion on the subject is psychometric at the expense of the theoretical-conceptual aspects, which are essential for an adequate interpretation of the results, a better understanding of the decision-making phenomenon and as a guide in the search for new data for future studies (Dalal et al., 2015).

More broadly, a systematic review of 66 studies (in English or Spanish) about decision making in psychology during the 2002-2012 period by using the key words 'Decision Making' or 'Choice' and 'Judgment' showed a great theoretical divergence in the decision models and an absence of work oriented towards the consensus of a coherent theoretical framework (Fernández Arbeláez, \& Villada Zapata, 2015). Furthermore, there are authors that have signaled that the assumption that the maximization concept would be a stable dispositional tendency when facing decisions has not been thoroughly tested and does not have empirical support (Harman, Weinhardt, \& Gonzalez. 2018). Contrarily, others affirm that there is enough evidence (Misuraca, Faraci, Gangemi, Carmeci, \& Micelli, 2015; Misuraca \& Fasolo, 2018). 
In an effort to reconcile the theoretical confusion, the fragmentation and the contradictory results, we can distinguish two recent approaches: i) Cheek and Schwartz (2016) proposed a new definition of two-component maximization, and ii) Misuraca, Faraci, Gangemi, Carmeci and Miceli (2015) proposed a new measure to assess maximizing, satisficing, and the new concept of minimizing.
In an effort to reconcile the theoretical confusion, the fragmentation and the contradictory results, we can distinguish two recent approaches: i) Cheek and Schwartz (2016) proposed a new definition of two-component maximization, and ii) Misuraca, Faraci, Gangemi, Carmeci and Miceli (2015) proposed a new measure to assess maximizing, satisficing, and the new concept of minimizing.

i) The new definition of two-component maximization of Cheek and Schwartz (2016) emphasizes that the essential aspect of maximization is the goal of identifying the optimal option. Among the fundamentals of this new definition, it is proposed that the search for the optimum takes place regardless of the DD and the HS searching, the first resulting from deciding, and the second not being exclusive to the maximizers.

This new concept of maximization has only two components: an optimal choice as the goal and a strategy to achieve the goal. The strategy consists of searching for the maximum number of alternatives and their comparison. Hence, the strategy could allow differentiating between a maximizer and a satisficer. For example, the former continues searching for alternatives even after making his or her decision while the satisficer stops his or her search after deciding (Cheek \& Schwartz, 2016; Dalal et al., 2015). Also, it is postulated that maximizers and satisficers could have equally high standards so this would define that maximization is not this, but the desire for the best (Cheek \& Schwartz, 2016).

From a psychometrical point of view, Cheek and Schwartz (2016) recommended the use of the Dalal's et al. (2015) 7-Item Maximizing Tendency (MTS-7) to measure goal for its psychometric properties, clarity, and the way it deals the concept of maximization. In fact, and for example, the MTS appears more theoretically and psychometrically valid than the Maximization Scale (MS) of Schwartz et al., 2012 (Dalal et al., 2015). Some literature using the MTS-7 shows that maximization is not related to negative indices of well-being (Dalal et al., 2015; Misuraca \& Fasolo, 2018), differing from the majority of evidence showing that there is a relationship between maximization (using MS or MI) and negative well-being indices (lyengar et al., 2006; Moyano Díaz, Cornejo, Carreño, \& Muñoz, 2013; Nenkov, Morrin, Ward, Schwartz, \& Huyan, 2008; Polman, 2010; Purvis, Ryan, \& Iyer, 2011; Schwartz, 2002; Turner, Rim, Betz, \& Nygren, 2012).

For the component strategy, they propose the SA subscale of the MI by Turner et al., (2012). Although it would contain items that go beyond the SA, it would be the most appropriate one until a more refined measurement is created. The SA (Turner, 2012) it was uncorrelated with any of the well-being indices and negatively correlated with the adaptive decision-making style. Subsequently, one positive relation between SA and SWL in Chilean university students was reported (Moyano Díaz, Martínez-Molina, \& Ponce, 2014).

ii) The new measure of maximization proposed by Misuraca et al. (2015) is the Decision Making Tendency Inventory (DMTI) (29 items, grouped in three factors and six sub-dimensions with Cronbach's alpha from .60 to .81) for measuring independent decision-making tendencies. The DMTI was built upon 289 undergraduate volunteers from the Italian Universities of Palermo and Messina, 56\% women, and a mean age 21.

Misuraca, Faraci, Gangemi, Carmeci and Miceli (2015) introduced and included two types of maximization in the DMTI -resolute and fearful-, two types of satisficing more and less ambitious- and two types of minimization -parsimonious and indolent. 
Pág 22

The aim of the present paper is fourfold: i) to examine the well-being indices correlation with the two-component maximization's new definition (Cheek \& Schwartz, 2014) using MTS-7 and SA for goal and strategy, respectively ii) to examine the well-being indices correlation with the two different types of maximizers -ResMax and FearMax-, iii) to relate the maximization goal and strategy measures with malaise indices: regret and DD and iv) to examine resolute and fearful maximization types with malaise indices: regret and DD.
The latter is a new concept as an opposite of the maximization tendency. The Resolute maximization (ResMax) measure is obtained with six items in which three are taken from the MTS-7. The Resolute maximizer is characterized by scrupulousness and perseverance but neither by regret nor SWL. The Fearful maximizer (FearMax) is characterized by a high need for scrupulousness and order (but not perseverance) and they show an association with a low level of SWL (and self-esteem and optimism) and a high level of regret. The decisions of the FearMax approach are characterized by a fear of making suboptimal decisions with sentiments of insecurity and inability to make good decisions and expectations of regret with respect to their choice. They engage in an overwhelming endless comparison process which results in procrastination of the decision, not choosing, or a regret for the choice made.

Contrarily, Misuraca et al. $(2015,114)$ speculate that the ResMax have a clear idea of which goals to achieve and meticulously process a large amount of information in order to achieve them with persistence and tenacity. FearMax, instead, process a large amount of information just out of their meticulousness and desire for order, without necessarily having a clear idea of the goals to achieve. So, the different characteristics of maximization construct and style -resolute vs. fearful- may clarify and explain previous maximization inconsistencies or contradictory outcomes.

\section{The present study}

The new two-component definition by Cheek and Schwartz (2016) and the DMTI conceptual basis and measures are interesting for clarifying concepts and understanding the ensemble of contradictory outcomes.

Therefore, the aim of the present paper is fourfold: i) to examine the well-being indices correlation with the two-component maximization's new definition (Cheek \& Schwartz, 2014) using MTS-7 and SA for goal and strategy, respectively ii) to examine the well-being indices correlation with the two different types of maximizers -ResMax and FearMax-, iii) to relate the maximization goal and strategy measures with malaise indices: regret and DD and iv) to examine resolute and fearful maximization types with malaise indices: regret and DD.

The hypotheses to verify in this study were: i) find no positive relationships between maximization as measured with the MTS-7 with well-being indices, ii)find no relationships between ResMax and well-being indices, iii) find negative relationships between FearMax and well-being indices, iv) find positive relationships between maximization as measured with the MTS-7 with malaise indices, v) find no positive relationships between the ResMax and malaise indices, vi) find positive relationships between the FearMax and malaise indices, vii) find negative relationships between FearMax and well-being indices.

\section{Method}

It is a descriptive and correlational study in which the instruments are applied simultaneously.

\section{Participants}

The sample consists of 624 volunteers of both sexes, 325 women (52.1\%) and 299 men $(47.9 \%)$ selected from a population of 333,789 adults with a maximum error range of $3.9 \%$. The mean age was 38.9 years $(S D=13.29)$ with a range between 18 and 79 years. They are workers from cities in central southern Chile, common citizens with a wide 
range of professions and activities including homeowners, trade workers, public employees, traders, professionals from different disciplines, technicians, self-employed (independent), or belonging to public and private companies and some retired. A sample of workers was used here to avoid the bias that can be present in most of the studies that are done with university students. All agreed to participate through informed consent.

\section{Instruments}

Eight instruments or subscales of instruments previously and adequately translated to Spanish were applied. We use MTS-7 (Dalal et al., 2015) to measure maximization following Cheek and Schwartz's (2016) suggestion for their new maximization definition. We also used two sub-scales of the DMTI to measure two different types of maximization: the ResMax (with five items, three of which are shared with the MTS-7) and FearMax (6 items). All scales were completed using 5-point agreement responses.

The MI (Turner et al., 2012): it measures maximization with two of three sub-dimensions: SA (12 items) and DD (12 items), where responses are obtained on a 5-point scale ranging from "Strongly Disagree" (1) to "Strongly Agree" (5). Here, SA of MI by Turner is understood as the strategy component of maximization.

The Regret Scale (Schwartz et al., 2002) (see Table 2): is a 5-item scale that measures on a 5-point response format ranging from "Strongly Disagree" (1) to "Strongly Agree" (5). The reported reliability index (Cronbach a) by these authors and other studies was from .67 to .71 (Moyano-Díaz et al., 2013).

The SWL Scale by Diener, Emmons, Larson, and Griffin (1985): with 5 items (Table $3)$, one of the most frequently used measures for global assessment of life satisfaction. The response scale consists of 5 levels ( $1=$ Strongly Disagree, 5 = Strongly Agree). The item-total correlation indices for reliability support reported by Diener et al. (1985) ranged from .61 to .81 , and the Chilean version had a $\mathrm{a}=.87$ and test-retest reliability of .82 (Moyano-Díaz, 2010).

The Subjective Happiness Scale (SHS) by Lyubomirsky and Lepper (1999): it measures happiness through 4 items to be answered in a format of 1 to 7 (from 'not very happy' to 'very happy'). The SHS is a scale in which participants are asked to state until which point, they consider themselves as happy people.

\section{Procedure}

The measure scales Goal (Dalal et al., 2015), DMTI, MI, Regret, SWL and, SHS have been previously translated and adapted to Spanish in Chile (Moyano Díaz, Palomo-Vélez, \& Mendoza-Llanos, 2016; Moyano Díaz et al., 2014; Moyano Díaz et al., 2013; Moyano Díaz, 2010; Moyano \& Ramos, 2007), obtaining adequate psychometric indices (see Table 1). This study was carried out within the framework of a research project reviewed and approved by the Scientific Ethics Committee of the University of Talca Folio $N^{\circ}$ 2017-08-EM, and was developed following the principles established in the Helsinki Declaration. The instruments were applied to the participants preceded by an informed consent.

The first step for data analysis was the calculation of Cronbach's Alpha Reliability Indicators and McDonald's Omega Reliability for all variables. The second step was to 
evaluate the correlations between the dimensions of maximization -Goal and Strategyand well-being and malaise indices: SWL and happiness and regret and DD to verify the hypotheses. All analyses were performed with JASP v.8.3 software.

\section{Results}

Initially, some descriptive and psychometric results concerning instruments reliability are reported. Afterwards, the correlations between the components of the maximization definition by Cheek and Schwartz (2016) and the two types of maximizers of Misuraca et al. (2015) in respect to the well-being and malaise indices are shown. Finally, the seven hypotheses are tested.

Descriptive statistics and reliability of the eight instruments are in Table 1.

Table 1. Descriptive statistics and reliability of the eight instruments or subscales.

\begin{tabular}{cccccccc}
\hline $\begin{array}{c}\text { Instruments } \\
\text { or sub-scales }\end{array}$ & Variable & N items & Mean & SD & Cronbach a & McDonald $\boldsymbol{\omega}$ & $\begin{array}{c}\text { Inter-item } \\
\text { correlation }\end{array}$ \\
\hline MTS-7 & Maximization & 7 & 3.45 & 0.63 & 0.73 & 0.74 & 0.28 \\
\hline $\begin{array}{c}\text { DMTI } \\
\text { (ResMax) }\end{array}$ & $\begin{array}{c}\text { Resolute } \\
\text { Maximization }\end{array}$ & 5 & 4.85 & 1.08 & 0.61 & 0.62 & 0.24 \\
\hline $\begin{array}{c}\text { DMTI } \\
\text { (FearMax) }\end{array}$ & $\begin{array}{c}\text { Fearful } \\
\text { Maximization }\end{array}$ & 6 & 4.26 & 1.16 & 0.62 & 0.63 & 0.21 \\
\hline S.A. of M.I & Strategy & 12 & 41.45 & 7.31 & 0.82 & 0.82 & 0.27 \\
\hline MI & $\begin{array}{c}\text { Decision } \\
\text { Difficulty }\end{array}$ & 12 & 37.64 & 4.45 & 0.81 & 0.85 & 0.28 \\
\hline RS & Regret & 5 & 3.08 & 0.77 & 0.72 & 0.74 & 0.34 \\
\hline SWL & $\begin{array}{c}\text { Life } \\
\text { Satisfaction }\end{array}$ & 5 & 24.91 & 6.07 & 0.83 & 0.84 & 0.51 \\
\hline SHS & Happiness & 4 & 5.33 & 0.96 & 0.69 & 0.76 & 0.40 \\
\hline
\end{tabular}

Goal= MTS-7; Strategy $=$ Search Alternatives; SWL= Satisfaction with Life

Regarding measure of goal, the MTS-7 (Dalal et al., 2015) presents a reliability of $a=.73$, and the other two DMTI maximization measures obtained values lower than 0.7. But, according to Briggs and Cheek (1986), the optimum level of homogeneity of a measure is produced when the inter-item correlation is in the range of .2 to .4, which is fulfilled here where the values reached for ResMax and FearMax are .24 and 21 , respectively. For this reason, they can be used as reliable instruments for the constructs they claim to measure. Thus, it was decided to use the mentioned dimensions with all the items proposed in the original instrument.

The measure of strategy of the MI (Turner et al., 2012) obtained the highest reliability here, $\alpha=.82$, and DD, regret, SWL and happiness scales also adequately presented Cronbach's Alpha and McDonald's Omega Reliability.

\section{Relationship between variables and hypothesis verification}

Inter-correlations among all measures are provided in Table 2. 
Table 2. Correlations between the two dimensions of maximization, two kinds of maximizers, and malaise and well-being indices.

\begin{tabular}{|c|c|c|c|c|c|c|c|c|c|c|}
\hline \multirow{2}{*}{$\begin{array}{c}\text { Author proposal } \\
\text { Cheek \& } \\
\text { Schwartz }\end{array}$} & \multirow{2}{*}{$\begin{array}{l}\text { Instruments } \\
\text { MTS-7 (Goal) }\end{array}$} & \multicolumn{2}{|c|}{$S A$} & \multicolumn{2}{|c|}{$D D$} & \multicolumn{2}{|c|}{ Regret } & \multicolumn{2}{|c|}{ SWL } & SHS \\
\hline & & .33 & $* * *$ & .17 & $* * *$ & .14 & $* * *$ & .01 & & .04 \\
\hline $\begin{array}{c}\text { two components } \\
\text { definition }\end{array}$ & $\begin{array}{l}\text { SA (of the MI) } \\
\text { (Strategy) }\end{array}$ & - & & .32 & $* * *$ & .24 & $* * *$ & -.12 & $* *$ & -.08 \\
\hline Misuraca et al. & Resolute Max & .16 & $* * *$ & .09 & $*$ & .08 & $*$ & .01 & & .05 \\
\hline (DMTI) & Fairful Max & .24 & $* * *$ & .53 & $* * *$ & .41 & $* * *$ & -.15 & $* * *$ & $-.14^{* * *}$ \\
\hline
\end{tabular}

Globally, concerning the definition of the two maximization components of Cheek and Schwartz's (2016) proposal-goal and strategy- a positive and significant correlation between both $(r=.33, p<.001)$ is observed. The goal and strategy components both appear to be related positively with malaise indices DD and regret, and the strategy registers the highest correlation with $\mathrm{DD}(r=.32, p<.001)$.

In respect to the two types of maximizers of the approach by Misuraca et al.. (2015), we can observe that both types also correlate with negative indices of well-being. The ResMax correlates very weakly with malaise indices -DD and regret- and the FearMax does correlate strongly with both those indices. The two types of maximizing reached $r=.21, p<.001$ between them, evidencing an ample range of differentiation.

With regard to the verification of the seven hypotheses, all were confirmed. The first hypothesis $(\mathrm{H} 1)$ concerning no positive relationship between maximization as measured with the MTS-7 and well-being indices was confirmed. Neither the goal nor the strategy components are positively or clearly related to SWL or happiness. Only SA with SWL reaches $r=-.12(p<0.1)$

In respect to the two types of maximizers, for the ResMax (H2) there are effectively no relationships with well-being indices, neither with SWL nor SHS. The third hypothesis $(\mathrm{H} 3)$ is also accepted because there are negative relationships between FearMax and well-being indices. The correlations between FearMax and SWL and SHS are negative and significant even though the values are weak.

In regard to the malaise indices, the fourth hypothesis $(\mathrm{H} 4)$ predicts finding positive relationships between maximization as measured with the MTS-7 - goal and strategy- with malaise indices, and it is accepted. Both components are correlated positively with regret and $\mathrm{DD}$. The fifth hypothesis $(\mathrm{H} 5)$ predicts not finding positive relationships between the ResMax and malaise indices and it was accepted. There are no positive correlations with DD nor regret. Only one significant, negative and low correlation between ResMax with SWL was found.

The sixth hypothesis $(\mathrm{H} 6)$ was confirmed, too. Positive relationships between FearMax and malaise indices were found. The correlations between FearMax with DD and regret are the highest found here. In the same line, the seventh hypothesis (H7) predicts finding negative relationships between FearMax and well-being indices, which was confirmed, too. There are significant correlations, although weak, in the negative direction as expected between FearMax with SWL and happiness. 
Concerning the concept of maximization, various authors have argued that the goal component (optimization) is most central to the core definition of maximizing (Dalal et al., 2015; Diab, Zhu, \& Hwang, 2015), but the results here show that of the maximization components, strategy is the one that appears to be more associated to malaise than goal. So, it seems that what maximizers do (strategy) and not what they want (goal) affects their well-being (Hughes \& Scholer, 2017).

\section{Discussion}

The eight instruments applied to a sample of working adults reached adequate levels of reliability and its inter-correlations support validity.

The results show positive correlations between the two maximization components of Cheek and Schwartz's (2016) definition -goal and strategy- with regret and a reasonable inter-colineality between them $(r=.33, p<.001)$. This suggests the existence of a common conceptual core and simultaneity abroad range of differentiation. So, the two components of the definition although related are independent and both contribute to comprehending maximization. This is confirmed when we observed the important differences where SA show a higher correlation than goal for all well-being and malaise indices, too. The fact that both maximization definition components -goal and strategy- correlate positively here with regret indicate that the maximization decision-making style is consistent and positively influences malaise. This is consist with the extensive literature from the USA and Europe about this relationship as cited in the introduction.

Concerning the concept of maximization, various authors have argued that the goal component (optimization) is most central to the core definition of maximizing (Dalal et al., 2015: Diab, Zhu, \& Hwang, 2015), but the results here show that of the maximization components, strategy is the one that appears to be more associated to malaise than goal. So, it seems that what maximizers do (strategy) and not what they want (goal) affects their well-being (Hughes \& Scholer, 2017). We assume that maximizers and satisficers -both- want the best (high standard) but, as we know, in the maximizers the strategy is a process that seems to remain running even after deciding and do not benefit from the reduction of dissonance after making the decision (Spark, Ehrlinger, \& Eibach, 2012). This may be at the base of their regret or more generally, malaise. The psychological effort in thinking and pondering before making a decision could probably explain maximizers' intense regret without ignoring that at the base a neurotic personality may be found; a factor that has been reported as important when predicting maximization (Purvis, Howell, \& lyer, 2011).

This explanation or alternative hypothesis is coherent with the description of Misuraca et al. (2015) concerning FearMax. They would have a high need for scrupulousness and order as well as have fear in making suboptimal decisions, experience feelings of insecurity and inability to make good decisions and expectations of regret with respect to their choice. They engage in an overwhelming endless comparison process the results in the procrastination of the decision, not choosing, or a regret for the choice made.

Regarding the two types of maximizers -resolute and fearful- the correlation between them is not high $(r=.21, p<.001)$, suggesting that both types are amply differentiated as Misuraca et al., (2015) suggested. From an empirical point of view, the negative emotional results of the maximization are negative for both types of maximizers (and -additionally- very similar when measured by the MTS-7 or the DMTI) but the magnitude varies greatly. So, when comparing FearMax with ResMax, the negative correlations with malaise indices are stronger for the former with DD and with regret $r=.53 p<.001$ and $r=.41 p<.001$ vs. $r=.09, p<.05$ and $r=0.8, p<.05$, respectively.

So, the correlations are higher in respect to the malaise indices corresponding to the SA component of the MI, and particularly for FearMax of the DMTI by Misuraca et al. (2015). This contributes to empirically clarify the conceptual differentiation between the two 
The results obtained here are added to those of a significant number of studies already cited, which show that there is more evidence to affirm the negative emotional consequences of maximization than harmlessness. For this reason, it seems better to accept the evidence definitively and neither continue arguing that maximization does not produce negative consequences for the decision maker nor searching for one measure of maximization that shows that it is not associated to negative emotional consequences. As we said earlier, the malaise or discomfort may be the price to pay for satisfying our ambition (Moyano Díaz. Martínez-Molina, \& Ponce, 2014). components of each proposal. The latter can help explain the contradictory results found regarding the relationships between maximization and its correlations with negative emotional outcomes when deciding, which are mostly positive and exceptionally negative. For example, if a maximization instrument is mainly constituted for 'goal' items, it will be more likely to obtain positive correlations with well-being indices (or, at least, weak correlations with malaise indices) and the contrary if it contains mainly 'strategy' items. It would not be strange that an examination of the more popular instruments shows that.

In this study, two similar outcome patterns are observed in the strength of the correlations. On the one hand, the goal component of maximization achieves positive correlations, albeit low, with DD and regret, as well as with the ResMax type. On the other, the SA component of the maximization and the FearMax type have stronger correlations since they are similar to each other in $\mathrm{DD}$ and regret.

Additionally, our results in this study with the Latin American, Chilean adult population shows other and expected meaningful correlations convergent with previously mentioned international literature: negative between the variables regret and SWL (Moyano-Díaz et al., 2014; Schwartz et al., 2002) as well as regret and happiness (Schwartz et al., 2002; Moyano et al., 2013), and a positive correlation between the SWL and happiness (Moyano-Díaz et al., 2014; Moyano et al., 2013; Moyano \& Ramos, 2007; Schwartz et al, 2002).

When comparing the DMTI maximization measures with that of MTS-7 and its correlations with indices of well-being and malaise, it can be observed that both correlate positively with SA, regret and DD. Additionally, it is clear here that the differentiation between the two types of maximizers -resolute and fearful- has empirical support in the Chilean adult population as well as being a very important contribution to Misuraca et al. (2015) for clarifying the maximization concept.

From another point of view, the regret experienced for this sample of adults is observed to be high, which appears in opposition with what is proposed by Misuraca et al. (2015). For these authors maximization explains less regret because the ResMax students are not associated with negative indices once they decide; they move on and continue without regret. Contrary, we observed here that both types of adult maximizers- experience regret (being much deeper for FearMax than ResMax). Perhaps more life experience provides greater empathy and awareness of consequences when making decision in adults than in young people, exacerbating the negative effect on malaise.

The results obtained here are added to those of a significant number of studies already cited, which show that there is more evidence to affirm the negative emotional consequences of maximization than harmlessness. For this reason, it seems better to accept the evidence definitively and neither continue arguing that maximization does not produce negative consequences for the decision maker nor searching for one measure of maximization that shows that it is not associated to negative emotional consequences. As we said earlier, the malaise or discomfort may be the price to pay for satisfying our ambition (Moyano Díaz, Martínez-Molina, \& Ponce, 2014).

We agree with the request of Misuraca et al. (2018) of not creating more instruments to measure maximization until the concept is clarified and to promptly agree on a definition of maximization among specialists. However, we go further. We think that 
From the theoretical perspective, our findings add to the growing knowledge concerning individual differences in decision making. From a cross-cultural perspective, our results show that in the Chilean Latin-American culture the relationship between decision making with well-being and malaise follow the same tendency as in USA and European culture. maintaining the focus on maximization as a concept and not on satisficing as a natural human tendency, as stated by Simon (1959), appears to be an ideological option very consistent with the values of a capitalist consumer market. Indeed, the literature on maximization has a lot of interest and application in the world of economics and the consumer market. Misuraca et al. (2015) advance with their DMTI by including items of measurement for three different application areas, including economics.

An important result from this study is that the two-component definition by Cheek \& Schwartz emphasized goal as the essential aspect of maximization (optimal versus good enough), but the discussion about this topic (Cheek \& Schwartz, 2016; Hughes \& Scholer, 2017; Schwartz, et al., 2002) and our results here suggest that strategy (more or less alternative searches) appears more important than goal. Strategy is more associated with indices of malaise than goal, particularly it appears positively associated with regret and with DD. In respect to the two types of maximizers of Misuraca et al. (2015) it is clear here that FearMax presents higher correlations with indices of malaise than ResMax.

In this context, the Luan and Li (2017) formulation makes sense since people always look for the optimal option and only differs when evaluating the feasibility to make decisions. We believe that this last factor -feasibility- can be part of the strategy and probably could be the real and specific differentiator aspect between maximizers and satisficers. We agree with Luan \& Li (2017) that the goal could be the same for maximizers and satisficers, but that the strategy characterizes the maximization decision process and particularly, the feasibility. When differentiating between maximizers and satisficers, the decision is a compromise between desirability and feasibility for the latter. Perhaps maximizers are willing to put forth more effort to face obstacles of less favorable or more difficult feasibility conditions than satisficers. They seek to optimize their market and life decisions and believe that it is worthwhile to look, find out and compare well before making their decisions. However, the market economy, and more generally capitalism, produces a society of disappointed citizens (Lipovetsky, 2008) and tired (Han, 2017).

Future studies are required to clarify this issue and explicitly assess whether satisficers are people less willing to sacrifice their comfort or well-being in order to achieve certain goals. Perhaps satisfiers are people more connected with themselves, less neurotic, or more mentally healthy, and verifying it constitutes a very interesting challenge for future studies.

From the theoretical perspective, our findings add to the growing knowledge concerning individual differences in decision making. From a cross-cultural perspective, our results show that in the Chilean Latin-American culture the relationship between decision making with well-being and malaise follow the same tendency as in USA and European culture. From a psychometrical point of view, the DMTI appears as a promising new instrument for the measurement of maximization behaviors by introducing two types of maximizers corresponding to ResMax and FearMax that are valid in the Chilean Latin-American culture, too.

Finally, the sample used here is quantitatively representative of the total adult population of the cities concerned, with a margin of error of less than $5 \%$. Therefore, the findings should be interpreted with certainty in this respect. 


\section{References}

Abbe, A., Tkach, C., \& Lyubomirsky. S. (2003). The art of living by dispositionally happy people. Journal of Happiness Studies, 4, 385-404. doi: http://dx.doi.org/10.1023/B:JOHS.0000005769.54611.3c

Besharat, A., Madik, D., \& Carrillat, F. (2014). Are maximizers blind to the future? When today's best does not make for the better tomorrow. Mak Lett, 25, 77-91. doi: http://dx.doi.org/10.1007/s11002-013-9243-4

Briggs, S. R., \& Cheek, J. M. (1986). The role of factor analysis in the development and evaluation of personality scales. Journal of Personality, 54(1), 106-148. doi: https://doi.org/10.1111/j.1467-6494.1986.tb00391.x

Chang, E.C., Lin, N.J., Herringshaw, A.J., Sanna, L.J., Fabian, C.G. Perera, M.J., \& Marchenko, V.V. (2011) Understanding the link between perfectionism and adjustment in college students: Examining the role of maximization. Personality and Individual Differences, 50, 1074-1078. doi: http://dx.doi.org/10.1016/j. paid.2011.01.027

Cheek, N., \& Schwartz, B. (2016). On the meaning and measurement of maximization. Judgment and Decision Making, 11(2), 126-146. doi: http://journal.sjdm. org/16/16129b/jdm16129b.pdf

Cote Rangel, L.P., \& García Barrera, A.M. (2016). Estrés como factor limitante en el proceso de toma de decisiones: una revisión desde las diferencias de género. Avances en Psicología Latinoamericana, 34(1), 19-28. doi: http://dx.doi.org/10.12804/ apl34.1.2016.02

Dar-Nimrod, I., Rawn, C. D., Lehman, D. R., \& Schwartz, B. (2009). The maximization paradox: The costs of seeking alternatives. Pers. and Individual Differences, 46, 631-635. doi: http://dx.doi.org/10.1016/j.paid.2009.01.007

Dalal, D. K., Diab, D. L., Zhu, X. S., \& Hwang, T. (2015). Understanding the construct of maximizing tendency: A theoretical and empirical evaluation. Journal of Behavior and Decision Making, 28, 437-450. doi: https://doi.org/10.1002/bdm.1859

Diab, D.L, Gillespie, M.A., \& Highhouse, S. (2008). Are maximizers really unhappy? The measurement of maximizing tendency. Judgment and Decision Making, 3(5) 364-370.

Diener, E., Larson Emmons, R.A., Larsen, R.J., \& Griffin, S. (1985). The satisfaction with the life scale. Journal of Personality Assessment, 49, 71-75. doi: https://doi. org/10.1207/s15327752jpa4901 13

Ďuriník, M., Procházka, J., \& Cígler, H. (2018). The Short Maximization Inventory. Judgment and Decision Making, 13(1) 123-136.

Fernández Arbeláez, J. I., \& Villada Zapata, J. (2015). Analysis of Evidence in Decision-Making Research between 2002 and 2012. Avances en Psicología Latinoamericana, 33(1), 105-120. doi: http://dx.doi.org/10.12804/apl33.01.2015.08

Harman, J. L., Weinhardt, J. M., \& González, C. (2018). Maximizing Scales Do Not Reliably Predict Maximizing Behavior in Decisions from Experience. Journal of Behavioral Decision Making, 31(3), 402-414. doi: https://doi.org/10.1002/bdm.2070

Hair, J.F., Anderson, R.E., Tatham, R.L., \& Black, W.C. (1999). Análisis Multivariante (5ª Ed.) Madrid: Prentice-Hall.

Han, B.-C. (2017). La sociedad del cansancio (2a Ed.). España: Herder.

Hughes, J., \& Scholer, A. A. (2017). When Wanting the Best Goes Right or Wrong: Distinguishing Between Adaptive and Maladaptive Maximization. Personality and Social Psychology Bulletin, 43(4), 570-583. doi: https://doi. org/10.1177/0146167216689065

lyengar, S., Wells, R., \& Schwartz, B. (2006). Doing better but feeling worse: Looking for the best job undermines job satisfaction. Psychological Science, 17, 143-150. doi: http://dx.doi.org/10.1111/j.1467-9280.2006.01677.x 
JASP Team. (2017). JASP (Version 0.8.3) [Computer software]. https://jasp-stats.org/ Lipovetsky, G. (2008). La sociedad de la decepción. Entrevista con Bertrand Richard. Barcelona, España: ANAGRAMA.

Luybomirsky, S., \& Lepper, H.S. (1999). A measure of subjective happiness: preliminary reliability and construct validation. Social Indicators Research, 46, 137-155. doi: https://doi.org/10.1023/A:1006824100041

Luan, M., \& Li, H. (2017). Good enough-compromise between desirability and feasibility: An alternative perspective on satisficing. J. of Experimental Social Psychology, 70, 110-116. doi: http://dx.doi.org/10.1016/j.jesp.2017.01.002

Misuraca, R., Faraci, P., Gangemi, A., Carmeci, F. A., \& Miceli, S. (2015). The Decision Making Tendency Inventory: A new measure to assess maximizing, satisficing, and minimizing. Personality and Individual Differences, 85, 111-116. doi: http:// dx.doi.org/10.1016/j.paid.2015.04.043

Misuraca, R., \& Fasolo, B. (2018). Maximizing versus satisficing in the digital age: Disjoint scales and the case for "construct consensus". Personality and Individual Differences, 121, 152-160. doi: https://doi.org/10.1016/i.paid.2017.09.031

Moyano-Díaz, E. (2010). Exploración de algunas propiedades psicométricas de las escalas de satisfacción vital, felicidad subjetiva y autopercepción de salud. En Moyano-Díaz, E. (Ed), Calidad de Vida y Psicología en el bicentenario de Chile (pp. 447-470). Santiago, Chile: Gráfika Marmor.

Moyano-Díaz, E., Martínez-Molina, A., \& Ponce, P. F. (2014). The price of gaining: maximization in decision-making, regret and life satisfaction. Judgment and Decision Making, 9(5), 500-509.

Moyano-Díaz, E. Cornejo, F., Carreño, M., \& Muñoz, A. (2013). Bienestar subjetivo en maximizadores y satisfascedores. Terapia Psicológica, 13(3), 373-380. doi: https://dx.doi.org/10.4067/S0718-48082013000300001

Moyano-Díaz, E., Palomo-Vélez, G., \& Mendoza-Llanos, R. (2016). Adaptación preliminar del Maximization Inventory (MI) de Turner et al. (2012) en muestra de estudiantes universitarios chilenos. Documento de trabajo (Working Paper), Grupo de Investigación en Calidad de Vida y Ambientes Saludables, Facultad de Psicología, Universidad de Talca (Chile).

Moyano-Díaz, E., \& Ramos, N. (2007). Bienestar Subjetivo: Midiendo satisfacción vital, felicidad y salud en población chilena de la Región del Maule. Universum, 22(2), 184-200. doi: http://dx. doi.org/10.4067/S0718-23762007000200012

Nenkov, G.Y., Morrin, M., Ward, A., Schwartz, B., \& Hulland, J. (2008). A short form of the maximization scale: Factor structure, reliability and validity studies. Judgment and Decision Making, 3, 371-388.

Newman, D. B., Schug, J., Yuki, M., Yamada, J., \& Nezlek, J. B. (2018). The negative consequences of maximizing in friendship selection. Journal of Personality and Social Psychology, 114(5), 804-824. doi: http://dx.doi.org/10.1037/pspp0000141

Parker, A. M., Bruine de Bruin, W., \& Fischoff, B. (2007). Maximizers versus satisficers: Decision Making styles, competence, and outcomes. Judgment and Decision Making, 2, 342-350.

Polman, E. (2010). Why are maximizers less happy than satisficers? Because they maximize positive and negative outcomes. J. of Behav. Dec. Making, 23, 179-190. doi: http://dx.doi.org/10.1002/bdm.647

Purvis, A., Ryan T.H., \& lyer, R. (2011). Exploring the role of personality in the relationship between maximization and well-being. Personality and Individual Differences, 50(3), 370-375. doi: http://dx.doi.org/10.1016/j.paid.2010.10.023

Richardson, C.M.E., Ye, H.J., Ege, E., Süh, H., \& Rice, K. G. (2014). Refining the measurement of maximization: Gender invariance and relation to psychological 
well-being. Personality and Individual Differences, 70, 229-234. doi: http://dx.doi. org/10.1016/j.paid.2014.06.048

Rim, H., Turner, B.M., Betz, N.E., \& Nygren, T. E. (2011). Studies of the dimensionality, correlates, and meaning of measures of the maximizing tendency. Judgment and Decision Making 6, 565-579.

Schwartz, B., Ward, A., Monterosso, J., Lyubomirsky, S., White, K., \& Lehman, D. (2002). Maximizing versus satisficing. J. of Personality and Social Psychology, 83, 1178-1197. doi: http://dx.doi.org/10.1037/0022-3514.83.5.1178

Schwartz, B. (2004). The paradox of choice: Why more is less. New York: Harper Perennial.

Schermelleh-Engel, K., Moosbrugger, H., \& Müller, H. (2003). Evaluating the Fit of Structural Equation Models: Test of Significance and Descriptive Goodness-ofFit Measures. Methods of Psychological Research Online, 8(2), 23-74.

Simon, H. A. (1955). A behavioral model of rational choice. Quart. J. of Economics, 59, 99-118. doi: http://dx.doi.org/10.2307/1884852

Spark, E.A., Ehrlinger, J., \& Eibach, R.P. (2012). Failing to commit: Maximizers avoid commitment in a way that contributes to reduced satisfaction. Personality and Individual Differences, 52, 72-77. doi: http://dx.doi.org/10.1016/i.paid.2011.09.002

Turner, B., Rim, H. B., Betz, N., \& Nygren, T. E. (2012). The Maximization Inventory. Judgment and Decision Making, 7, 48-60.

Weinhardt, J.M., Morse, B.J., Chimeli, J., \& Fisher, J. (2012). An item response theory and factor analysis examination of two prominent maximizing tendency scales. Judgment and Decision Making, 7, 644-658. 